\title{
Business and Information Systems Engineering and Marketing
}

\author{
DOI 10.1007/s12599-013-0264-6
}

\section{The Authors}

Prof. Dr. Martin Spann ( $₫)$

Institute of Electronic Commerce and Digital Markets

LMU Munich

80539 Munich

Germany

spann@bwl.Imu.de

Prof. Dr. Oliver Hinz

Professur für Wirtschaftsinformatik -

Electronic Markets

Technische Universität Darmstadt

64289 Darmstadt

Germany

hinz@wi.tu-darmstadt.de

Prof. Dr. Vandana Ramachandran Operations and Information Systems David Eccles School of Business

University of Utah

SLC 84112, Utah

USA

vandana@business.utah.edu

Published online: 2013-04-20

This article is also available in German in print and via http://www. wirtschaftsinformatik.de: Spann $M$, Hinz O, Ramachandran V (2013) Wirtschaftsinformatik und Marketing. WIRTSCHAFTSINFORMATIK. doi: 10 . 1007/s11576-013-0363-5.

(C) Springer Fachmedien Wiesbaden 2013
Electronic media have tremendously changed marketing's opportunities and challenges. The interactive nature of the Internet has empowered consumers, for example by enabling them to actively engage in the pricing process via interactive and dynamic pricing mechanisms (Bichler et al. 2010; Hinz et al. 2011; Skiera et al. 2005). Furthermore, consumers can exchange information on products and prices within their social networks, which helps them take better consumer decisions but puts additional effort on the business models of online retailers to account for consumers' social interaction (Hinz and Spann 2008).

However, the Internet also provides new opportunities for marketers: recommender systems enable online retailers to cross-sell and up-sell, and they change the way products are sold (Hinz and Eckert 2010; Mertens 1997). Advertisers can much better evaluate the advertising effectiveness and efficiency in electronic media compared to traditional media such as print or television (Animesh et al. 2010; Ghose and Yang 2009). Rich data and user interaction enable personalized products, advertising and the individualized management of customer relationships (Ray et al. 2005; Tam and Ho 2006). Furthermore, new forms of marketing in search engines, social networks, and via mobile devices such as location-based services have emerged (e.g., Kumar and Benbasat 2006).

Hence, consumers leave many digital footprints in the form of transactional data and user-generated content which provide multiple opportunities for enterprises to grow. However, this information incorporates the challenge that companies have to turn these data into actionable intelligence. These data can be used to create new products, reduce operating costs, and develop a better understanding of the consumers' needs. As the data contain a lot of noise and are hard to handle because of sheer size (catchword: big data), marketers need the input of business information systems departments and researchers to create knowledge from these immense data volumes.

But then, the big data opportunity also requires a critical reflection with respect to consumers' privacy concerns. Therefore researchers in this area have to actively participate in the ongoing discussion on data protection. It is necessary to find a balance between the consumers' rights on the one hand and potential innovations based on these data on the other hand. We refer to the ongoing discussion on data protection in Europe, see for example http://www.dataprotectioneu.eu.

All the described developments have been enabled by recent developments in information systems. Thus, business information systems did not only enable these new opportunities in digital marketing, but the intersection of marketing and BISE also provides very promising research opportunities. In this special focus issue, we want to highlight these research opportunities and advance research on BISE and Marketing.

The goal of this special focus was to increase our understanding of the opportunities and challenges for business information systems research at the intersection with marketing. The call for papers generated a total of 18 submissions, which went through a double-blind review process. Of these submissions, five papers were accepted for this special focus.

The five contributions in this issue show a width of topics and methods which reflect the scope of this promising research field. Research topics range from consumer reviews and electronic word-of-mouth, online social networks to deal-of-the-day platforms and revenue management. The articles employ a broad methodological spectrum from simulation to qualitative and quantitative empirical work using survey and observational data.

The first two papers focus on how online consumers use information from their peers in order to take purchase decisions. Lis studies the factors that drive the credibility of online consumer recommendations. Testing her theoretical predictions based on a survey of 643 consumers, she finds that the sender characteristics expertise and trustworthiness are the most important factors influencing the credibility of electronic word-ofmouth and subsequently consumers' purchase decision. Scholz and Dorner study the 
factors influencing the perceived helpfulness of online consumer reviews by using observational data of several thousand reviews across six product categories at Amazon. They find that the perceived review helpfulness is affected both by the characteristics of the review itself and by the context of other reviews available. Both papers provide numerous implications for consumers, online communities, and online retailers on the provision, use, and management of online consumer reviews.

The third and fourth papers study aspects related to customer management and pricing. Gerlach, Cleophas, and Kliewer study the impact of airline code share alliances on the performance of revenue management systems using a simulation study. They outline the marketing benefits and information systems challenges of airline codeshare alliances, and they quantify their impact on bookings and revenues. Krasnova, Veltri, Spengler, and Günther study the drivers of customer loyalty to so called "deal of the day" platforms using a combination of qualitative and quantitative empirical methods. They find that customer loyalty to such platforms is largely driven by monetary incentives, but requires a sufficient quality of the product/service. Both papers by Gerlach, Cleophas, and Kliewer and by Krasnova, Veltri, Spengler, and Günther show the opportunities of new marketing and pricing practices for sellers and retailers, but also the challenges to optimally employ them.

Finally, Probst, Grosswiele, and Pfleger provide an extensive overview of the state of the art in identifying influential users in online social networks which is a hot topic for online marketers. Obviously not all consumers are equally active and influential in online social networks, and maintaining a good relation to these opinion leaders seems to be advisable for companies engaging in business-to-consumer markets.

In the interview, Dr. Jörg Lübcke of Burda Digital shares his insights on digital technologies' impact on marketing and business models the media industry. He emphasizes that digitalization has two impacts on the media industry: strong challenges for their traditional business models, and great opportunities to build new business models that leverage the potential of digital technologies.

\section{References}

Animesh A, Ramachandran V, Viswanathan S (2010) Research note - quality uncertainty and the performance of online sponsored search markets: an empirical investigation. Information Systems Research 21(1):190-201

Bichler M, Gupta A, Ketter W (2010) Designing smart markets. Information Systems Research 21(4):688-699

Ghose A, Yang S (2009) An empirical analysis of search engine advertising: sponsored search in electronic markets. Management Science 55(10):1605-1622

Hinz O, Eckert J (2010) The impact of search and recommendation systems on sales in electronic commerce. Business \& Information Systems Engineering 2(2):67-77

Hinz O, Hann I-H, Spann M (2011) Price discrimination in e-commerce? An examination of dynamic pricing in name-your-own-price markets. MIS Quarterly 35(1):81-98

Hinz O, Spann M (2008) The impact of information diffusion on bidding behavior in secret reserve price auctions. Information Systems Research 19(3):351-368

Kumar N, Benbasat I (2006) Research note - the influence of recommendations and consumer reviews on evaluations of websites. Information Systems Research 17(4):425-439

Mertens P (1997) Recommender systems. WIRTSCHAFTSINFORMATIK 39(4):401-404

Ray G, Muhanna WA, Barney JB (2005) Information technology and the performance of the customer service process: a resource-based analysis. MIS Quarterly 29(4):625-652

Skiera B, Spann M, Walz U (2005) Erlösquellen und Preismodelle für den Business-to-ConsumerBereich im Internet. WIRTSCHAFTSINFORMATIK 47(4):285-294

Tam KY, Ho SY (2006) Understanding the impact of web personalization on user information processing and decision outcomes. MIS Quarterly 30(4):865-890 